\title{
Showing the impact of school-library cooperation through digital monitoring
}

\author{
Kees Broekhof \\ Sardes Educational Services \\ PO Box 2357, 3500 GJ Utrecht \\ k.broekhof@sardes.nl \\ The Netherlands
}

\begin{abstract}
As part of the national Dutch Library at School program, a digital monitor has been developed which collects data on pupils, teachers, schools and school libraries. This article describes the aims, the content and the use of the monitor, as well as the context in which it was developed. The monitor is described as a multi-purpose instrument for practical, policy and research purposes. Examples of data collected in primary and secondary schools are presented and discussed. Specific attention is given to the role of public library staff can play in using the monitor to optimize collaboration with schools.
\end{abstract}

Keywords: Monitoring, School-library cooperation, Reading promotion, School library, Public library

\section{Introduction}

How can we, as librarians, make our cooperation with schools more effective? More targeted? More tailored to the needs of individual schools, forms and pupils? And how can we show that our work with schools actually has an impact on pupil and teacher behavior? These are the questions that the Dutch Library at School monitor seeks to answer. It does so by annually providing clear-cut figures on developments in pupils' reading motivation and behavior, teachers' reading promotion behavior and school reading promotion policy at pupil, school, local, regional and national levels.

The Library at School monitor is part of the Dutch national Library at School program, in which it has been used for three years in primary schools. In this contribution we will look at monitor in the wider context of the Library at School program and consider specifically the results of the recently completed first round of data collection in secondary schools.

\section{The Library at School}

The impact of reading on language development has been extensively investigated (Clark \& Rumbold, 2006; Mol \& Bus, 2011). Research studies consistently show that frequent reading correlates with positive developments in various domains of language development, such as vocabulary growth, reading comprehension, decoding skills, spelling, grammatical knowledge 
and writing skills (Krashen, 2004; Mol \& Bus 2001; Kortlever \& Lemmens, 2012). This evidence constitutes the scientific rationale behind the Dutch 'Library at School' program.

The Library at School is a national program seeking to promote reading among pupils in primary and secondary schools by improving cooperation between schools and public libraries and creating high quality libraries in schools. The program is part of the national Art of Reading initiative, which was launched by the Ministry of Education, Culture and Science in 2008 and which includes, besides the Library at School, Boekstart (the Dutch version of the British Bookstart project) and a program aimed at creating regional reading promotion networks. The overall aim of the Art of Reading is to promote a culture of reading among children nationwide. The program, which received a budget of EUR 20 million in the period 2008-2015, is managed jointly by the Reading Foundation and the Royal Library.

Three rounds of data collection: 2012-2013, 2013-2014, 2014-2015

Participants in the program:

primary schools: 2,385

public libraries: 119 (74.4\%)

Participants in the monitor (2012-2015):

1,100 primary schools (ca. $10 \%$ of all primary schools)

96,000 primary school pupils

9,600 primary school teachers

1,000 reading consultants (public library staff)

Textbox 1: The Library at School - facts and figures

The initial focus of the Library at School program was on primary schools. Since 2014, successful pilot studies have been conducted to extend the concept to childcare centers (connected with Boekstart) and to secondary schools. The ultimate goals is to reach children with reading promotion activities from an early age until the end of secondary school.

Research shows that early exposure to books and storybook reading, followed by independent reading at primary and secondary school age (and beyond) has a accumulative effect on language development (Mol \& Bus, 2011). Following the successful dissemination of the program in primary schools, then, current attempts are focusing on the periods before and after primary school.

\section{A note on school libraries in the Netherlands}

School libraries in the Netherlands are generally not run by teacher-librarians, as in many other countries. They may be run by a librarian from the public library, by volunteers (parents), by pupils or by a school librarian (whose professional background is not necessarily school library work or teaching). Libraries of schools participating in the Library at School program are on average open for 10 hours per week.

Textbox 2: A note on school libraries in the Netherlands 


\section{The Library at School monitor}

The Library at School monitor is a digital instrument on the internet that is used to collect annually data on pupil reading behavior, teacher reading promotion behavior, school reading promotion policies and school libraries (run in collaboration with public library staff). Libraries and schools can use these data to evaluate the results of their cooperative work and to make decisions about steps to take next and thus enhance the effectiveness of their collaboration. To this end, the monitor collects information on the following topics:

Pupils

- reading motivation

- reading frequency

- visits to public and school libraries

- home reading culture

- perception of school library

- information skills

Teachers

- reading promotion behavior in the classroom

- information skills

- information teaching skills

- perception of the school library

Library staff

- the school library (e.g., collection, opening hours, staffing)

- school reading promotion policy (including curriculum time for silent reading)

- school media education policy

- pupils' book borrowing rates (school library and public library)

- library services offered to schools

\section{Data collection and feedback}

Data are collected once per year, through digital questionnaires administered to pupils, teachers and library staff. Local public libraries recruit schools for participation in the monitor as part of the standard Library at School 'package' for schools, which generally includes the creation or upgrading of the school library, in-school support by public library staff (ranging from one to several hours per week) and school participation in the monitor. In addition to the standard package, the local libraries provide services tailored to the schools' specific needs. The libraries receive concise standardized reports on each of the schools participating in the monitor, showing graphs with the key data on pupil and teacher behaviors, set off against national average figures. In addition, library staff (the so-called 'reading consultants') have the opportunity to enter the database and to create tailored reports for individual schools, geared to the school's own reading promotion policy priorities. The reading consultant presents the results to the teachers in a meeting, interprets the data with them and discusses what steps should be taken in the next period. 


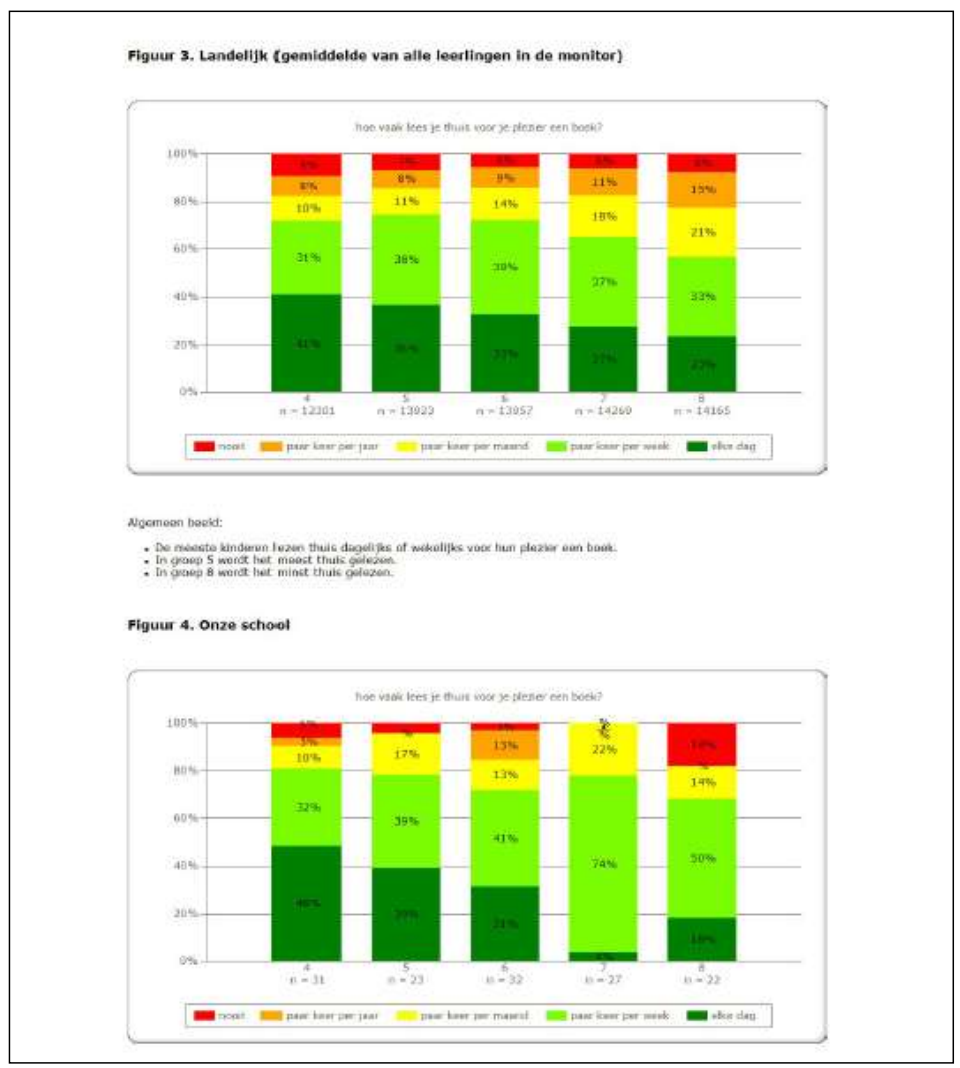

Figure 1 - page from a standard report

Figure 1 shows a page from a standard report on a school, presenting national average figures (figure 3, top) and school figures (figure 4, bottom) for reading frequency per year group, ranging from 'never' (red), to 'every day' (dark green).

\section{Levels of data}

Data in the monitor can be viewed at six levels:

1. national level

2. provincial level

3. municipal level

4. library work region level (does not always coincide with municipal borders)

5. school level

6. classroom level (also by gender)

These different levels of data make it possible for libraries to carry out analyses, for different purposes. Most important, of course, are the analyses at school and classroom level, as these are used inform cooperation decisions at the individual school level. But libraries can also look at developments at the municipal level, with a view to reporting to the local authorities (who fund the local library); or at the provincial level, to inform provincial library policy making.

The huge amount of data, collected across the country, also makes it possible to conduct large-scale analyses at the national level. This is not the work of individual libraries, but of 
universities and other specialized institutes. One such analysis has looked at the impact of school libraries on reading motivation (Huysmans et al., 2013); another has analyzed the overall picture emerging from the data (Broekhof \& Broek, 2014).

In short, the different levels of data make it possible for the monitor to be used as a multipurpose instrument: as a work instrument, for making practical decisions about school-library cooperation at the everyday work level; as a policy instrument, for collecting baseline data, formulating policies, evaluating policies and accounting to local authorities; and as a research instrument, for conducting analyses to inform national project management and the scholarly community.

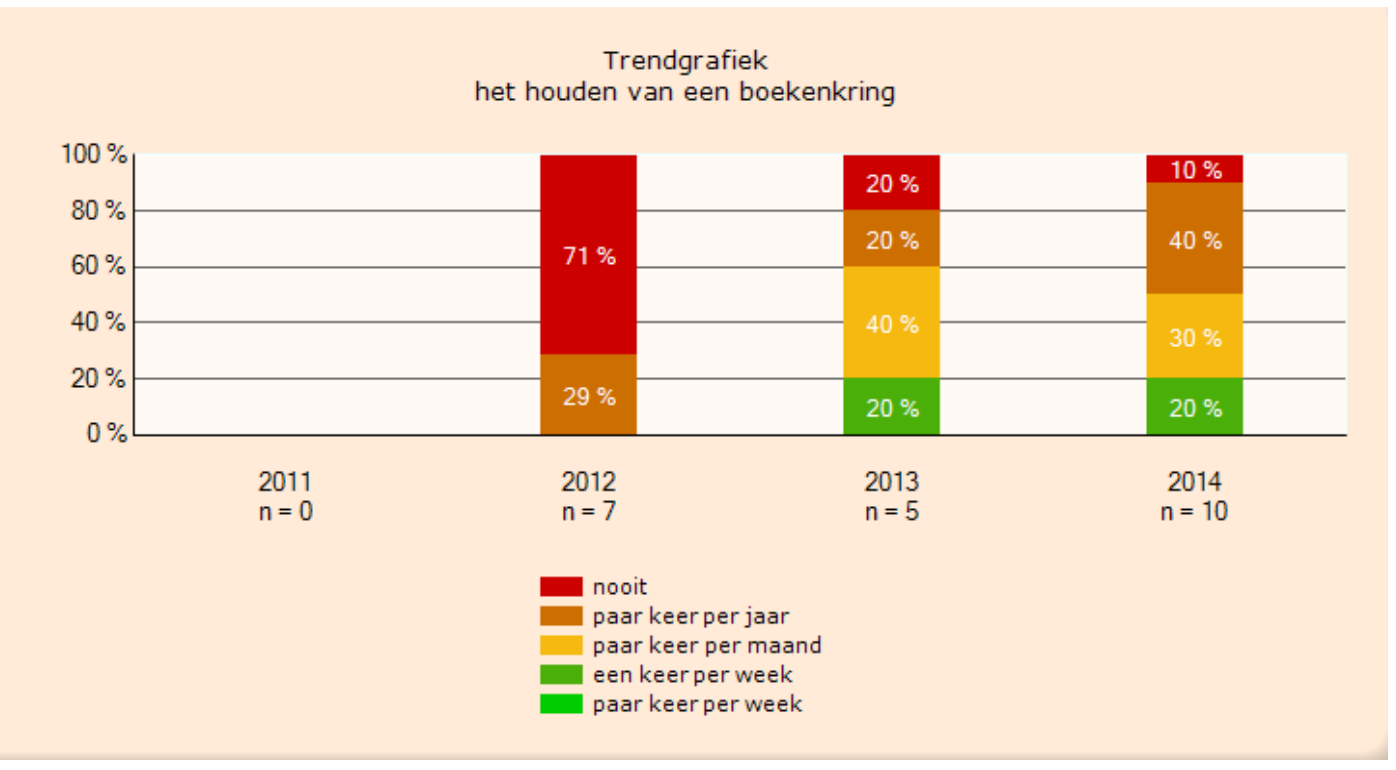

Figure 2 - Percentage of teachers from one school reporting to hold a book circle in their form in 2012, 2013, 2014 frequencies ranging from 'never' (red), via 'several times per year' and 'several times per month' to 'once a week' (dark green); the highest possible frequency 'several times per week' is not reported.

Figure 2 shows the reported frequency of holding reading circles in one school in three consecutive years. If a school has adopted reading circles as a priority in its reading promotion policy, these percentages will be discussed by the reading consultant with the teachers, addressing the question of to what extent the goal set for the year concerned has been attained. It is for instance possible that the goal for 2014 was: all teachers hold a book circle at least several times per year. This goal has not been attained. Incidentally, the percentages appear to show a positive development over the years, but exact interpretation is hampered by changes in the numbers of respondents - unfortunately a well-known obstacle in the use of the monitor.

\section{The monitor in secondary schools}

In 2014, following a successful pilot project, the monitor was made accessible to a limited number of secondary schools. It was decided to focus on junior secondary vocational schools (vmbo), i.e. the lower strands of secondary education, as pupils in these schools are considered to be in greater need of the linguistic benefits of reading than their peers in more academic types of education. 
Working with the monitor in secondary schools in more complicated than in primary schools. First of all, secondary schools are larger organizations, catering for populations of on average 1,400 pupils. This makes it unfeasible to organize a data collection in which all the pupils participate. Secondly, the relations between teachers and pupils are different, as teachers do not work with just one form, as in primary schools, but with various forms, which they see a limited number of hours per week; moreover, not all specialized teachers (such as auto mechanics teachers) consider their pupils' language development as their responsibility. This makes it more difficult to use the teacher as a change agent to change pupils' reading habits. Finally, secondary schools may already have a school library, staffed or not, which can make cooperation with the 'outside' public library more complicated.

Given the considerations above, the working model used in primary school was adjusted as follows. The reading consultant decides with the head teacher and the teachers who are directly involved in the project (generally language teachers and tutors) which year groups to involve in the project. The monitor questionnaires are then administered to a sample of 25 percent of the pupils and the teachers in these year groups. The results are fed back by the reading consultant in a meeting with the teachers in the sample and other teachers who are invited but not required to attend. If the school has a staffed school library, the school librarian is also involved in the project. The reading consultant from the public library and the school librarian decide among themselves how to divide tasks and responsibilities.

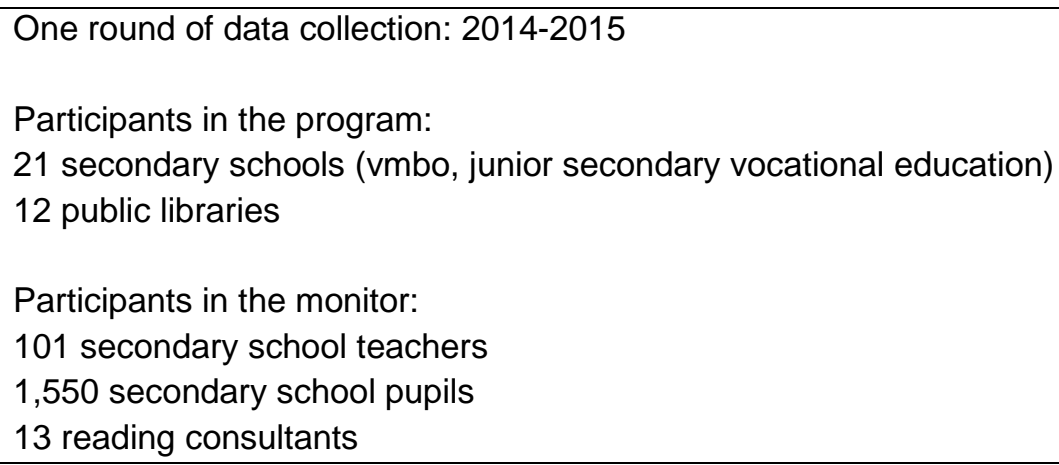

Text box 3: The Library at School monitor in secondary schools - facts and figures

\section{First outcomes}

Let us now look at a selection of the outcomes of the first round of data collection in vmbo schools. The monitor holds a huge amount of data. To look at even a representative sample goes beyond the scope of this contribution. We shall therefore look at a small, but telling selection, relating to reading motivation, teacher behavior and perceptions of the school library. 
2014

Hoe vaak lees je in je vrije tijd voor je plezier een boek?

| resultaten per: leerjaar |

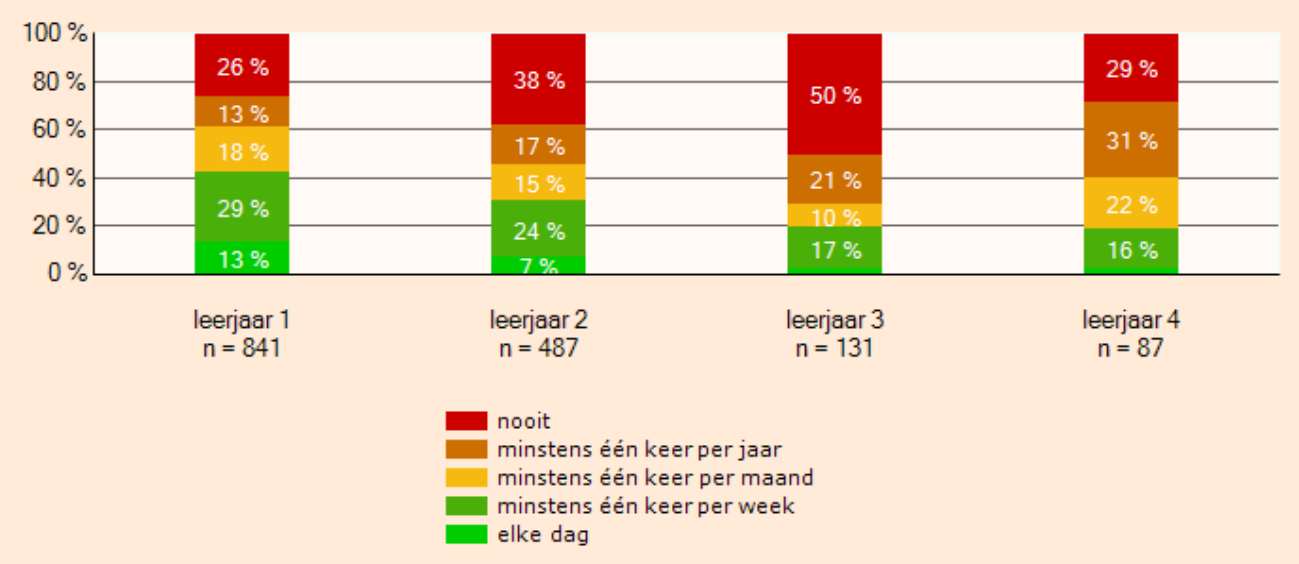

Figure 3 - reported reading frequency by pupils in junior secondary vocational schools, national averages, by form

Figure 3 shows how often pupils report to read for pleasure in their leisure time. 'Leerjaar 1 ' is the first form; frequencies range from 'never' ('nooit', red), via 'at least once a year', 'at least once a month' and 'at least once a week' to 'every day' ('elke dag', bright green). The high percentage of non-readers is probably explained by the fact that language-delayed pupils are overrepresented in this type of school; many of them were low attainers as well as reluctant readers in primary school. Surprisingly, the downward trend in reading frequency is not continued to the fourth form, where the percentage of non-readers suddenly declines from 50 percent in the third form to 29 percent in the fourth.

Let us now look at the figures for one particular school:

2014

Hoe vaak lees je in je vrije tijd voor je plezier een boek?

| resultaten per: leerjaar |

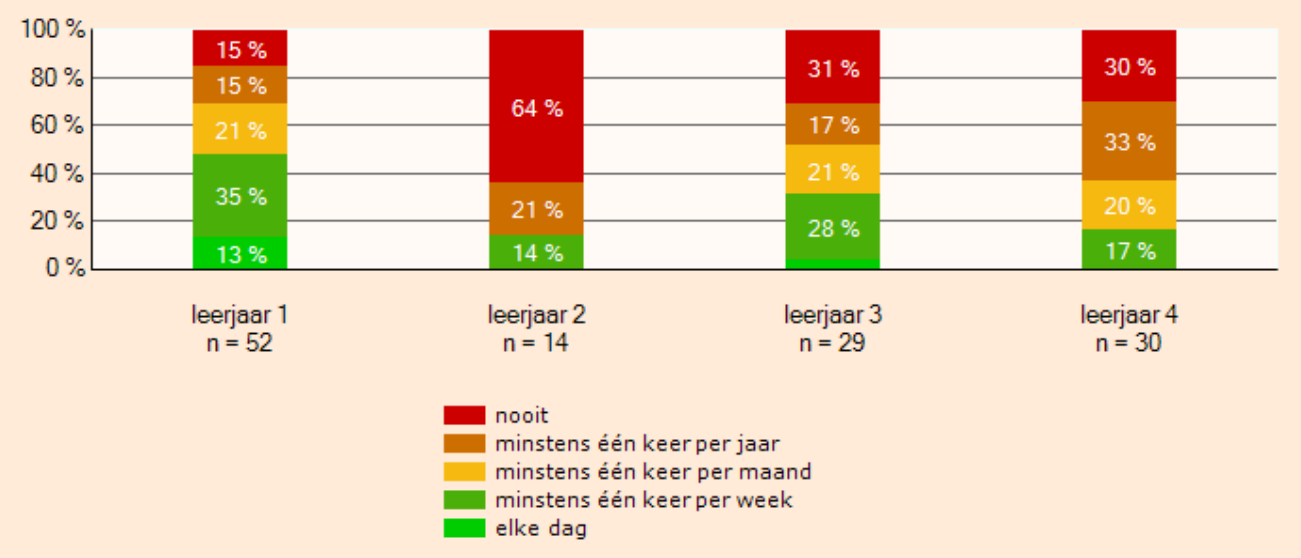

Figure 4 reported reading frequency by pupils in one school, by form 
Figure 4 shows data similar to those in figure 3 , from one school. The figure shows that the reported reading frequency is highest in year 1 and lowest in year 2 . If we disregard year 2 (on account of the low number of respondents), it is clear that the downward trend continues from year 1 tot year 4 . In the discussion with the teachers, these figures will be compared with the national averages. The reading consultant and the teachers will attempt to interpret the school data and to decide what measures might be called for to reduce the decline.

2014

Hoe vaak verwijst u vmbo-leerlingen naar de openbare bibliotheek?

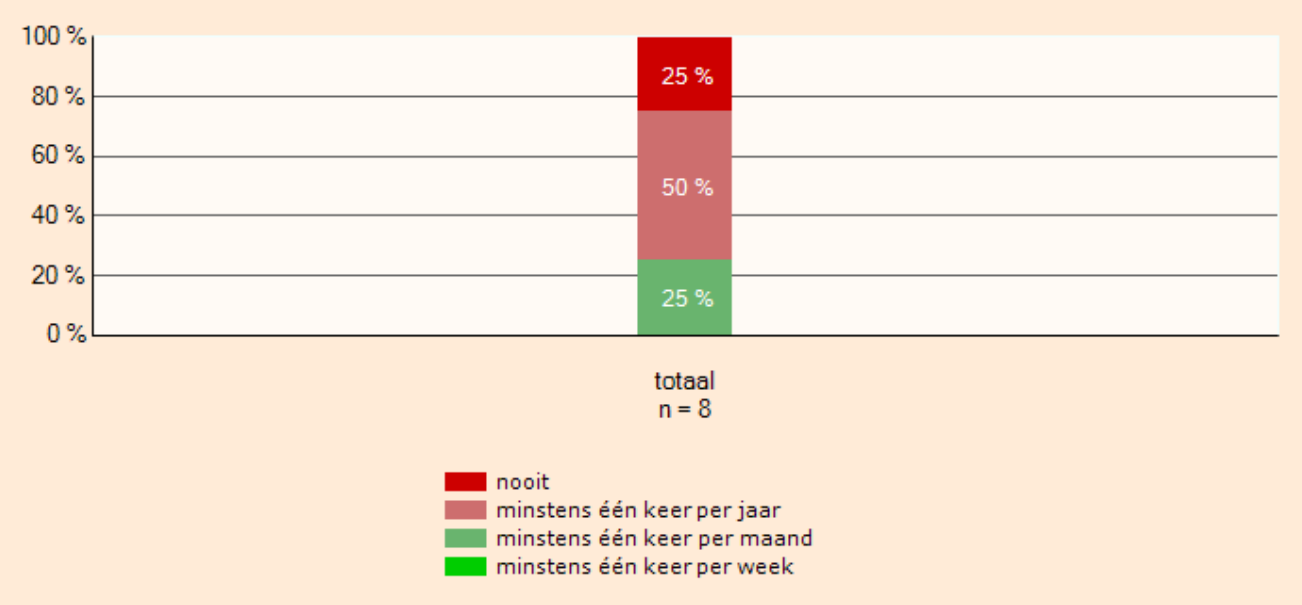

Figure 5 - Reported number of times teachers from one school refer pupils to the public library, frequencies ranging from 'never' (bright red), to 'at least once a month' (dark green); the highest possible frequency 'at least once a week' is not reported.

Figure 5 shows the number of times teachers from one school refer pupils to the public library. It appears that three quarters of the teachers 'never' or 'at least once year' refer pupils to the public library. This would certainly be a topic for discussion during the meeting between the reading consultant and the teachers, even though teachers report to refer pupils more frequently to the school library (not in this figure). This might result in the formulation of a 'SMART' goal for the next period: 'all teachers refer pupils at least once per month to the public library'. The next round of data collection will reveal whether this goal is reached. 
2014

de leesboeken in de mediatheek/schoolbibliotheek spreken mij aan | resultaten per: leerjaar |

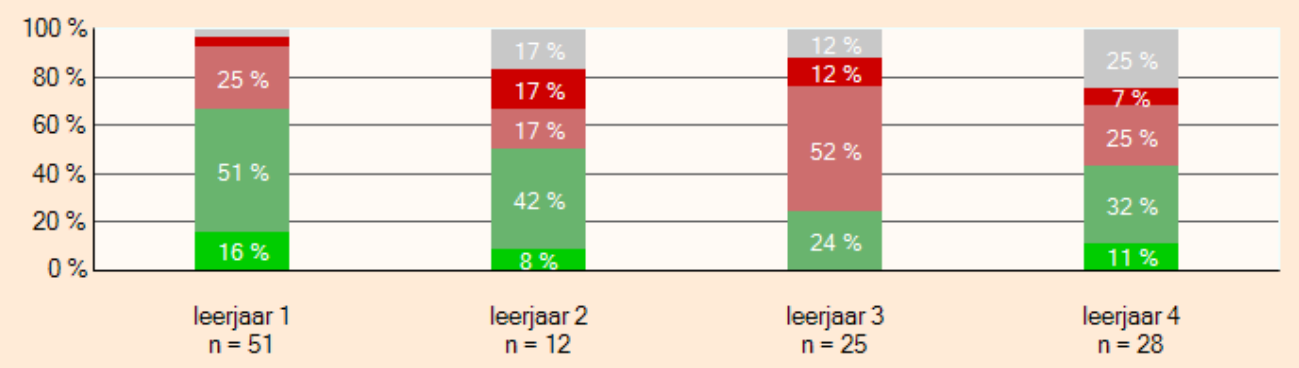

niet van toepassing

helemaal mee oneens

mee oneens

mee eens

helemaal mee eens

Figure 6 - One school's pupils' level of agreement with the statement 'I think the novels in the school library are attractive', levels ranging from 'not applicable' (e.g. pupil does not visit the school library), 'totally disagree' (bright red) to 'totally agree' (bright green).

Figure 6 shows the extent to which pupils in one school agree with the statement 'I think the novels in the school library are attractive'. It appears that 67 percent of first form pupils agree with this statement (highest score); in year 3, 24 percent of pupils agree with this statement (lowest score). This is an interesting topic for discussion. Is the collection less suitable for third-year pupils? If so, how is it that a much higher proportion of fourth-year pupils do find the collection attractive? As is often the case, the figure tells only part of the story and it is up to the reading consultant and the teachers to discover what is needed to improve pupils' perceptions (and use!) of the school library.

\section{Next steps?}

It is clear from the first round of data collection in secondary schools that the monitor offers interesting and useful data for libraries and school staff. At the same time, there are also a number of problems that have yet to be solved. Firstly, the representativity of the data is an issue. Low response rates make the data less reliable. This is also a well-known problem with the primary school monitor - one that we have not yet been able to solve satisfactorily, but that we will need to continue to look at. Second, how do we move from data on a sample of pupils and teachers to changing the entire school reading culture? How to make every teacher feel responsible for contributing to a positive reading climate in school? How to make all pupils susceptible to such a climate, taking into account the differences between avid readers and obstinate non-readers? This is a question that needs to be addressed by the librarians and the teachers who are actually carrying out the project in a particular school. Evaluation of the experiences in schools in the wake of the first round of data collection will have to show whether the monitor in its present form provides a useful basis for improving the reading climate in junior vocational secondary schools and, consequently, for supporting pupils' language development. 


\section{Conclusion}

The monitor is a powerful multi-purpose instrument for optimizing school-library collaboration, providing libraries and schools with rich data on pupils, teachers, schools and school libraries, which they can use to take informed decisions for further targeting their cooperation. The monitor is part of the Library at School program, which includes, besides the monitor, a variegated toolbox supporting librarians to follow up on the monitor with materials, projects and services. A recent study has shown that in primary schools participating in the Library at School program, pupils attain higher scores on standardized reading comprehension tests (Nielen \& Bus, 2015). Hopefully, this success will be repeated in secondary schools.

\section{Note}

The concept of the Library at School monitor was developed by Sardes Educational Services, Utrecht, and Thomas van Dalen consulting, Amsterdam, on a commission by the Art of Reading program. The technical infrastructure was developed by DESAN Research Solutions, Amsterdam.

\section{References}

Broekhof, K. \& Broek, M. (2014), Lezen meten: een basis voor beleid. Amsterdam: Stichting Lezen.

Clark, C. \& Rumbold, K. (2006), Reading for pleasure: a research overview. London: National Literacy Trust.

Huysmans, F., Kleijnen, E., Broekhof, K. \& van Dalen, T. (2013). The library at school: Effects on reading attitude and reading frequency. Performance Measurement and Metrics, 14 (2).

Kortlever, D. \& Lemmens, J. (2012), Relaties tussen leesgedrag en Cito-scores van kinderen. Tijdschrift voor Communicatiewetenschap, 40, 1, pag. 87-105

Krashen, S. (2004), The Power Of Reading: Insights From The Research. Westport, Connecticut/London: Libraries Unlimited; Portsmouth, NH: Heinemann. 2nd edition.

Mol, S.E. \& Bus, A.G. (2011), 'To read or not to read: a meta-analysis of print exposure from infancy to early adulthood.' Psychological Bulletin, 137, 2, 267-296.

Nielen, T. \& Bus, A. (2015), 'Leesmotivatie stimuleren: bibliotheek op school onder de loep'. JSW, april, 6-8. 